Editorial

\title{
Infant Mortality and Obstetric Assistance's Quality
}

\section{Mortalidade infantil e qualidade da assistência obstétrica}

\author{
Regina Amélia Lopes Pessoa de Aguiar ${ }^{1}$ Ana Maria Arruda Lana ${ }^{2}$ \\ ${ }^{1}$ Department of Obstetrics and Gynecology, Faculdade de Medicina, \\ Universidade Federal de Minas Gerais (UFMG), Belo Horizonte, Minas \\ Gerais, Brazil \\ 2 Department of Pathology and Forensic Medicine, Faculdade de \\ Medicina, UFMG, Belo Horizonte, Minas Gerais, Brazil \\ Rev Bras Ginecol Obstet 2016;38:479-481.
}

A worldwide acknowledged way of evaluating the life conditions of a population, in particular or in general, is to use health indicators that may be represented as rates or ratios. Such indexes are essential for the quality of the planning of programs and services, interfering directly in their efficiency. Furthermore, those indicators reflect substantially the quality of the assistance provided to the individuals. The relationship between women's life conditions and infant mortality is unquestionable, especially regarding family planning and obstetric assistance.

Infant mortality corresponds to the number of deaths of infants per 1,000 live births, in a given year, in the population living in a specific geographic area. In general, this number reflects the socioeconomic development and environmental infrastructure, as well as the access to and the quality of the resources available for maternal and child health care. Infant mortality has 3 important components: early neonatal mortality, which estimates the number of deaths among live births in the first 6 days of life; late neonatal mortality, which estimates the number of deaths among live births between 7 and 27 days of life, and post neonatal mortality, which is calculated using the number of deaths among live births between 28 and 364 completed days of life. The neonatal component is the one that suffers the influence of socioeconomic and women's health conditions the most, as well as that of the prenatal, childbirth and newborn assistance quality. Nevertheless, the coefficients that best reflect women's quality of life, and mainly of prenatal, childbirth and newborn assistance quality, are the perinatal mortality rate and the maternal mortality ratio. Perinatal mortality is represented by the number of deaths during the perinatal period (fetus deaths after 22 completed weeks of pregnancy up to 6 completed days after birth) per a total of 1,000 births (the total of live births and fetus deaths) in the population living in a specific geographic area, in a given year. The ratio of maternal deaths represents the number of maternal deaths per 100 thousand live births to mothers who live in a specific geographic area, in a given year. Maternal deaths are the ones that happen during the pregnancy or up to 42 days after its ending, regardless of the pregnancy's duration or the mother's geographic location, due to any cause related with or aggravated by pregnancy, or by measures adopted in relation to it, excluding accidental or incidental causes. A significant limitation for the correct estimation of such coefficients is the percentage of deaths and births not informed to the health system. In calculating maternal mortality, another important limitation for the indicator's accuracy is the incorrect filling out of death certificates that, at times, does not make explicit the existence of pregnancy in the chain of events that directly or indirectly led to the death of the woman of childbearing age. ${ }^{1}$

Aiming at qualifying the understanding of both infant and maternal deaths, many countries, including Brazil, incorporated in their epidemiologic surveillance actions for the monitoring of the deaths of women of childbearing age. This monitoring places declared maternal deaths (Decree nr. 1.119 , of June $\left.5^{\text {th }}, 2008\right)^{2}$, and infant and fetal deaths (Decree nr. 72, of January $\left.11^{\text {th }}, 2010\right)^{3}$ in the category of events that require mandatory investigation in public and private health services. As important as having a correct

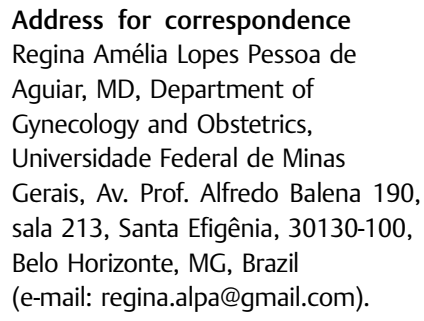

DOI http://dx.doi.org/ $10.1055 / \mathrm{s}-0036-1593777$. ISSN 0100-7203.
Copyright $\odot 2016$ by Thieme Publicações License terms Ltda, Rio de Janeiro, Brazil

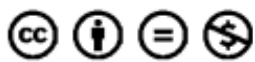


counting of infant, perinatal and maternal deaths is the comprehension of the factors associated to these deaths. The maternal, infant and fetal deaths prevention committees are organizations that congregate governmental institutions and organized civil society and work by giving visibility to, following and monitoring these deaths. By evaluating the quality of the assistance provided to pregnant women, during childbirth, and to the infant in its first year, the committees, subsidize public policies for maternal-infant health by proposing actions that may result in the reduction of mortality. These committees fundamentally have an educational and formative character and act confidentially. Although they are invaluable tools for analyzing the deaths, many institutions and municipalities do not keep them active.

In January of 2016, the journal The Lancet published a series entitled "Ending Preventable Stillbirth", in which it mentions that $\sim 2.6$ millions of fetuses are stillborn per year around the world, and 98\% of these cases happen in low and middle-income countries. Data show that $50 \%$ of those deaths happen during child labor and delivery. It is also emphasized the great impact that such losses have over families, health professionals, societies and governments. The series includes 5 articles written by more than 210 authors from 43 different countries; ${ }^{4-8}$ its global launch, organized by the International Stillbirth Alliance, happened on January $18^{\text {th }}, 2016$, in London, and it was live broadcasted to many countries. The School of Medicine of the Universidade Federal de Minas Gerais (UFMG) was one of the global headquarters where several members of the academic and civil societies watched the broadcast. Before the broadcast, there was a debate about the reality, the impact and the intervention prospects for reducing stillbirth in the state of Minas Gerais. After the debate, the participants watched the broadcast of the whole event. One of the points of the publication that stands out is the verification that stillbirth is an ignored tragedy. Several countries do not treat stillbirth as a relevant epidemiologic event, which generates enormous difficulty in monitoring its number. Although it is well established that most of these deaths are preventable, that their occurrence affects significantly socially disadvantaged women, especially ethnic minorities, black women, unemployed and/or poor women, and that stillbirth is a tragedy for the families that may have lasting social, psychological and financial effects, the impact of this kind of loss is a topic not properly considered by health professionals, by other family members or by society as a whole. Regarding this scenario, the articles of the series highlight that it is essential that organized and planned investments are made to accelerate the reduction of stillbirths in the whole world. Based on the data published in 2011 by the same journal, it was identified that the stillbirth rate dropped, on average, $2 \%$ per year between 2011 and 2015. Such reduction was lower than that of maternal deaths (average of $3 \%$ ) or of postnatal deaths of children under 5 years old (4.5\%). In 2014, the World Health Organization approved the target for 2030 of 12 or less stillbirths per 1,000 live births in each country. This goal can only be achieved if government, health professionals and society change their behavior facing stillbirth. It is necessary to give visibility to the problem; it is indispensable to include the monitoring and interventions for the reduction of stillbirth in the governmental agendas; it is critical to establish targets to be achieved. It is also urgent to include in under graduation and graduation courses curricula the discussion of stillbirth, not only on epidemiologic grounds and causal investigation, but also evoking the understanding of the impact of each death for the woman/family/society. Finally, it is imperative to remove women who had their pregnancies interrupted by fetal death from solitude and neglect. Health professionals' (physicians, nurses and other health professionals) attitude can make the difference in these parents' lives in that moment. Services provided with respect, including good quality in mourning attention, may reduce the negative impacts for the woman/couple/family. In general, from the assistance point of view, actions that may interfere in stillbirth rates are the same that recognizably determine the reduction of maternal and neonatal mortality ratio. Obstetric assistance with effective prevention practices against the aggravations to maternal and fetal health represents one of the bases for quality obstetrics. Such assistance should offer appropriate identification and treatment of maternal complications, such as arterial hypertension, diabetes, restriction in the intrauterine growth, and infections, with the conduction of labor based in the best scientific evidences and with a team trained to conduct childbirth without complications and to intervene appropriately in intrapartum urgencies.

According to DATASUS' (the department of informatics for the public health care system in Brazil) ${ }^{9,10}$ data, perinatal mortality in Brazil is estimated only in states where the final index (coverage and regularity of the system of information about mortality [SIM]) is equal to or greater than $80 \%$, and the SINASC (information system on live births) coverage is at least $90 \%$. Thus, only the Southern region could have the perinatal mortality rate calculated for all its states in the period between 2010 and 2013. This rate was not calculated for any state in the North and Northeast regions. In the Southeast region, only the state of Minas Gerais had not calculated the perinatal mortality rate, while in the Midwest, calculation was made available only referring to the states of Mato Grosso do Sul and Distrito Federal. The lowest perinatal mortality rate was found in the state of Rio Grande do Sul (12.8 per 1,000 live births in 2013) and the highest in the state of Rio de Janeiro (17.8 per 1,000 live births in 2011. In $2014,32.1345$ fetal deaths were declared, 25.688 of which had gestational age reported to be 22 weeks or more and 3.466 had gestational age reported as ignored. This scenario demonstrates the fragility of our epidemiological data.

In this number of RBGO, two articles that have a direct or indirect intimate relation to this editorial are published. ${ }^{11,12}$ In the first one, "Spatial Approach to Perinatal Mortality in São Paulo State from 2003 to 2012", the authors analyze perinatal mortality rates in the 645 municipalities of the state of São Paulo in two periods (2003 to 2007 and 2008 to 2012). They identify a significant global reduction comparing the 2 periods, with a drop of $8.4 \%$ in this rate. Nevertheless, 
the numbers found are still much higher than the estimated for developed countries. Through a Moran map construction, a spatial statistical technique that aims at identifying areas where values distribution may present a specific pattern associated to its geographic location, it was possible to identify the municipalities that presented the higher reduction of perinatal mortality rates, as well as municipalities that need a special attention regarding the processes of maternal and perinatal health assistance. The study also allowed the correlation between perinatal mortality and life conditions in each municipality, showing that the higher rates are concentrated in the municipalities with worse health and life quality indicators, including maternal schooling. The second study, "Factors Associated with Infant Mortality in a Northeastern Brazilian Capital", is a retrospective cohort based on secondary data of births and deaths of infants whose mothers lived in the municipality of Teresina (Piauí) in 2011. It makes an analysis using a hierarchical model according to socioeconomic, assistance, obstetric and biological determiners. The authors demonstrate that, for the distal-level of infant mortality determination (mother's socioeconomic conditions and the kind of institution that performed childbirth), the characteristics maintained as statistically significant were maternal age, schooling and occupation. In the intermediate level (obstetric antecedents, kind of pregnancy and of childbirth, and the number of prenatal consultations), the kind of pregnancy and childbirth were the most relevant. In the proximal-level (newborn's biological characteristics), the gender was a characteristic with no association to the mortality rate. Although this second study does not include stillbirth data, it signals to the importance of caring for women's life conditions and health, as well as for prenatal and childbirth assistance, as these are determining factors of infant death risk.

In 2015, the United Nations defined the Sustainable Development Goals (SDGs) as part of a new agenda that must conclude the Millennium Development Goals (MDGs). ${ }^{13}$ The agenda, that includes 17 goals and 169 targets, places before each one of us a commitment of citizenship to be fully kept. Governments and civil society must be mobilized to keep the global commitment of ending poverty, promoting prosperity and the well-being of all, protecting the environment, and facing climate changes. The challenges for our country are significant, specifically in maternal-infant health. Gynecology and obstetrics are some of the specialties that may be the difference in the results achieved. Teamwork, with proper training and qualification of the professionals; dignified working conditions and respect to the individual, to the community and to the environment must be the motto of our professional exercise. This is the invitation, the challenge and the certainty that it is possible to change our future.

\section{References}

1 Rede Interagencial de Informação para a Saúde. Indicadores básicos para a saúde no Brasil: conceitos e aplicações. 2a ed. Brasília (DF): Organização Pan-Americana da Saúde; 2008

2 Brasil. Ministério da Saúde [Internet]. Portaria ${ }^{\circ} 1.119$, de 5 de junho de 2008. Regulamenta a vigilância de óbitos maternos. 2008 [citado 2015 Maio 8]. Disponível em: bvsms.saude.gov.br/ bvs/saudelegis/gm/2008/prt1119_05_06_2008.html

3 Brasil. Ministério da Saúde [Internet]. Portaria n ${ }^{\circ} 72$, de 11 de janeiro de 2010. Estabelece que a vigilância do óbito infantil e fetal é obrigatória nos serviços de saúde (públicos e privados) que integram o Sistema Único de Saúde (SUS). 2010 [citado 2015 Maio 8]. Disponível em: bvsms.saude.gov.br/bvs/saudelegis/gm/2010/ prt0072_11_01_2010.html

4 Heazell AE, Siassakos D, Blencowe $\mathrm{H}$, et al; Lancet Ending Preventable Stillbirths Series study group; Lancet Ending Preventable Stillbirths investigator group. Stillbirths: economic and psychosocial consequences. Lancet 2016;387(10018):604-616

5 Frøen JF, Friberg IK, Lawn JE, et al; Lancet Ending Preventable Stillbirths Series study group. Stillbirths: progress and unfinished business. Lancet 2016;387(10018):574-586

6 Lawn JE, Blencowe H, Waiswa P, et al; Lancet Ending Preventable Stillbirths Series study group; Lancet Stillbirth Epidemiology investigator group. Stillbirths: rates, risk factors, and acceleration towards 2030. Lancet 2016;387(10018):587-603

7 Flenady V, Wojcieszek AM, Middleton P, et al; Lancet Ending Preventable Stillbirths study group; Lancet Stillbirths In HighIncome Countries Investigator Group. Stillbirths: recall to action in high-income countries. Lancet 2016;387(10019):691-702

8 de Bernis L, Kinney MV, Stones W, et al; Lancet Ending Preventable Stillbirths Series study group; Lancet Ending Preventable Stillbirths Series Advisory Group. Stillbirths: ending preventable deaths by 2030. Lancet 2016;387(10019):703-716

9 Brasil. Ministério da Saúde. DATASUS [Internet]. C.2 Taxa de mortalidade perinatal. 2013 [citado 2015 Jun 12]. Disponível em: http://tabnet2.datasus.gov.br/cgi/idb2013/c02c.htm

10 Brasil. Ministério da Saúde. DATASUS [Internet]. Óbitos fetais Brasil. 2014 [citado 2015 Jun 12]. Disponível em: http://tabnet. datasus.gov.br/cgi/deftohtm.exe?sim/cnv/fet10uf.def

11 Venâncio TS, Tuan TS, Vaz FPC, Nascimento LFC. Spatial approach of perinatal mortality in São Paulo State, 2003-2012. Rev Bras Ginecol Obstet. 2016;38:492-498

12 Santos SL, Santos LB, Campelo V, Silva AR. Factors associated with infant mortality in a Northeastern Brazilian Capital. Rev Bras Ginecol Obstet. 2016;38:482-491

13 United Nations. Sustainable Development Knowledge Platform [Internet]. Transforming our world: the 2030 Agenda for Sustainable Development. 2015 [cited 2015 Jan 25]. Available from: https://sustainabledevelopment.un.org/post2015/ transformingourworld $<0\}$ 